\title{
Uma análise sobre a aceitação de líderes: o caso da Guarda Civil de Mossoró (RN)
}

\section{An analysis on the Acceptance of leaders: the case of the Civil Guard of Mossoró (RN)}

\author{
ARTHUR WILLIAM PEREIRA DA SILVA* \\ HELAINE CRISTINE CARNEIRO DOS SANTOS** \\ BRENDA NATHÁLIA FERNANDES OLIVEIRA*** \\ FRANCISCO IGO LEITE SOARES*** \\ ANA LÚCIA DE ARAÚJO LIMA COELHO*****
}

\section{RESUMO}

Com o aumento da complexidade das organizações, devido a avanços nos diversos elementos que as compõem, o líder é cada vez mais proeminente nesse espaço, pois sob suas mãos repousa a responsabilidade de gerenciar esses recursos em busca de atingir os objetivos. Dessa forma, percebe-se a importância da aceitação dele por seus liderados. Este estudo busca testar a hipótese: há maior aceitação de líderes quando ocorre maior consenso quanto à aceitação dos critérios que os levaram à liderança. Para tanto foi desenvolvido um estudo quantitativo, utilizando-se princi-

* Universidade Potiguar - UnP. Doutorando em Administração pela Universidade Potiguar (UNP); Mestre em Ambiente, Tecnologia e Sociedade pela Universidade Federal Rural do Semiárido (UFERSA); Mestrando em Administração pela Universidade Federal da Paraíba (UFPB); Especialista em Gestão Empresarial pela Universidade Potiguar (UNP). arthurwilliamadm@hotmail.com

** Universidade Federal da Paraíba - UFPB. Mestranda em Administração pela Universidade Federal da Paraíba. helainecristine@hotmail.com.

*** Universidade Norte do Paraná - UNOPAR. Especializanda em Saúde Pública pela Universidade Norte do Paraná (Unopar). Graduada em Nutrição pela Universidade Potiguar (UNP). nutricionistabrendanathalia@gmail.com.

**** Faculdade Diocesana de Mossoró - FDM. Mestre em Engenharia de Petróleo e Gás pela Universidade Potiguar (UnP); Especialista em Gestão Empresarial pelas Faculdades Integradas de Jacarepaguá (FIJ) e em Docência no Ensino Superior pela Universidade Potiguar (UnP). igoleite.fas@gmail.com.

***** Universidade Federal da Paraíba - UFPB. Doutora em Administração e Turismo pela Universidade do Vale do Itajaí/UNIVALI (2012); mestre em Administração (2000). alalcoelho@gmail.com. 
palmente testes de média e variâncias pareadas, na Guarda Civil Municipal de Mossoró (RN), que conta com um efetivo de 275 guardas, dos quais 50 participaram da pesquisa. Os resultados evidenciaram que os líderes que apresentaram maior aceitação foram de fato selecionados pelo conjunto de critérios que apresentou o maior consenso em relação à sua aceitação. Dessa forma, conclui-se que a hipótese foi confirmada na instituição.

Palavras-chave: líderes; aceitação; critérios; seleção; liderados.

\section{Abstract}

With the increasing complexity of organizations, due to advances in the various elements that compose them, the leader is increasingly prominent in this space, because in your hands rests the responsibility to manage these search resources to achieve the goals. Thus, we see the importance of acceptance of these by their team. This study aims to test the hypothesis: there is greater acceptance of leaders when there is greater consensus on the acceptance of the criteria that led them to lead. For a quantitative study both been developed using mostly mean tests and pairwise variances, the Municipal Civil Guard Mossoró (RN), which has a staff of 275 officers, of which 50 participated. Results showed that the leaders who showed greater acceptance were actually selected by the set of criteria that had the highest consensus on their acceptance. Thus, it is concluded that the hypothesis was confirmed in the institution. Keywords: leaders; acceptance; criteria; selection; led.

\section{INTRODUÇÃo}

A liderança tem sido um campo bastante estudado para a compreensão dos fenômenos organizacionais, tanto no âmbito acadêmico quanto no prático. Entender os critérios que levam alguém à posição de liderança e, sobretudo, o papel do líder nas organizações modernas têm atraído considerável atenção.

Para Schein (2004), liderança é a capacidade de influência que um indivíduo exerce sobre outro. $\mathrm{O}$ autor diferencia liderança de gestão ou administração, defendendo a ideia de que a liderança é capaz de exercer transformação, modificar culturas, diferentemente da gestão ou administração, que atuam dentro da cultura existente. Dessa forma, o líder assume uma posição de destaque e é o principal precursor de novas ideias. 
Daft (1999) afirma que liderança é um relacionamento influente entre líderes e seguidores que pretendem reais mudanças que reflitam os seus propósitos partilhados. De acordo com Bryman (1996, p. 280), líder é alguém que "define a realidade organizacional por meio da articulação de uma visão, que é o reflexo de como ele ou ela define a missão da organização e os valores que a suportam".

Várias são as abordagens sobre o tema. Schein (1982) associa a liderança a um tipo de contrato psicológico realizado entre as partes, colaboradores e organização, pelo qual a autoridade é exercida de forma legítima (quando baseada principalmente no consenso entre os liderados quanto aos critérios que levaram os líderes às suas posições de liderança) ou ilegítima (imposta com base no poder, coerção e na punição). O autor afirma ainda que grande parte do poder do líder emerge dos próprios liderados, da sua aceitação ou não destes.

Com base no pressuposto teórico de Schein (1982) quanto à base de poder da autoridade legítima, decidiu-se neste artigo testar empiricamente a hipótese $\mathrm{H} 1$ de que há maior aceitação de líderes quando ocorre maior consenso quanto à aceitação dos critérios que os levaram à liderança. Para isso foi escolhida a Guarda Civil Municipal de Mossoró (RN), por se tratar de uma instituição que vem passando por um processo de mudança nos seus critérios de seleção de líderes, bem como por ser de médio porte - conta atualmente com cerca de 275 colaboradores - e estar situada numa cidade de médio porte, com uma população estimada em cerca de $288 \mathrm{mil}$ habitantes ${ }^{1}$, o que a coloca como a segunda maior do estado do Rio Grande do Norte.

A relevância teórica deste trabalho se dá por proporcionar o teste empírico de um pressuposto teórico altamente relevante para a área de liderança e que foi pouco testado em âmbito internacional e principalmente nacional. Já a relevância prática vem do fato de fornecer à instituição pesquisada um diagnóstico completo das bases de poder utilizadas por seus líderes, bem como uma avaliação específica sobre a aceitação dos critérios que os levaram à liderança, e por fim uma avaliação da aceitação deles. Sob a posse dessas informações,

IBGE, 2015. Disponível em: http://cidades.ibge.gov.br/xtras/perfil.php?codmun=240800. 
a instituição poderá revisar, caso ache necessário, os seus processos de estabelecimento de critérios de seleção de lideranças e também buscar modificar as bases de poder utilizadas, caso ache adequado.

\section{REFERENCIAL TEÓRICO}

\subsection{Liderança}

Etimologicamente a palavra liderar significa conduzir, portanto líder é aquele que conduz um grupo ao alcance de determinado objetivo. Vergara (2003) afirma que liderança é a capacidade de realizar influência sobre determinados indivíduos. Concomitantemente, Robbins (1999) também defende essa ideia. Chiavenato (1994, p. 147) entende que:

A liderança é um fenômeno tipicamente social que ocorre exclusivamente em grupos sociais. Podemos defini-la como uma influência interpessoal exercida numa dada situação e dirigida através do processo de comunicação humana para a consecução de um ou mais objetivos específicos. [...] a liderança é um tipo de influenciação entre pessoas: [...] na qual uma pessoa age no sentido de provocar o comportamento de uma outra, de maneira intencional.

Para Fiedler (1967, apud BERGAMINI, 1994, p. 103):

A preocupação com a liderança é tão antiga quanto a história escrita: A república de Platão constitui um bom exemplo dessas preocupações iniciais ao falar da adequada educação e treinamento dos líderes políticos, assim como da grande parte dos filósofos políticos que desde essa época procuraram lidar com esse problema.

Como pode-se perceber, ao longo da história a liderança foi objeto de interesse de estudos e pesquisas associadas ao comportamento humano, com ênfase na política e, posteriormente, no âmbito organizacional, em virtude do seu impacto diante das equipes, e nos resultados das empresas (HOGAN; HOGAN, 2004; NIRENBERG, 2004; YUKL, 2008; SCHEIN, 2009). 
O papel do líder tornou-se de fundamental importância na condução dos negócios. Schein (1996) o define como um agente de mudanças. Bornstein e Smith (1996) enfatizam que a verdadeira liderança ocorre quando os seguidores decidem abraçar seus líderes porque acreditam neles e na articulação de suas visões. Sendo assim, pode-se perceber o quanto o papel do líder é relevante para a organização e o quanto esse "papel" precisa estar legitimado perante o grupo.

\subsection{Legitimidade da liderança}

No início dos estudos organizacionais, durante o período da escola clássica, científica e até mesmo no início dos estudos humanistas nas organizações, pouca atenção era dada às expectativas e necessidades dos colaboradores, pois focavam-se demasiadamente as expectativas e necessidade organizacionais. Porém, com o avanço dos estudos organizacionais tem-se percebido maior consideração para com as expectativas e necessidades dos colaboradores.

Nesse sentido de evidenciar que as relações de trabalho são compostas por dois lados interessados, Schein (1982) apresenta o conceito de contrato psicológico entre organização e colaborador. Para o autor, tais relações são pautadas em uma espécie de contrato psicológico assinado entre as partes, no qual estão contidas as expectativas delas quanto ao que se espera da relação. De um lado, estão as expectativas dos colaboradores, que vão desde salários, horas de trabalho e benefícios até reconhecimento, segurança e proteção; de outro, as da organização, que envolvem lealdade do funcionário, manutenção dos segredos da organização e a preocupação com a imagem desta, até níveis elevados de motivação e esforço, quando necessários.

Segundo Schein (1982), esse contrato é mutável e se modifica de acordo com as variações nas necessidades de ambas as partes. Ainda de acordo com o autor, "[...] um elemento fundamental do contrato psicológico é a expectativa da organização de que um membro novo irá aceitar o sistema de autoridade dessa organização".

Para Schein (1982), a autoridade pode se dar de duas formas: ilegítima e legítima. A primeira é aquela baseada no poder, ou seja, que se vale da força bruta, da manipulação de recompensas, 
punições e informações para controlar as pessoas. Esse tipo de autoridade desconsidera a escolha dos outros, como também que estes possuem as próprias necessidades e expectativas quanto à aceitação do sistema de autoridade da organização. Dessa forma, fica evidente que o poder do líder não está no grupo ou na aceitação deste pelo grupo, mas sim nas ferramentas coercitivas de que se vale para fazer os colaboradores executarem a sua vontade.

Já a autoridade legítima é aquela na qual há consenso entre os membros de uma organização quanto à base ou critérios sobre os quais assentam a regra ou lei, ou aos critérios que determinam quem será elevado à posição de liderança ou autoridade. De acordo com Schein (1982, p. 20), “uma lei só será obedecida se houver consenso quanto ao método pelo qual as leis são feitas; os operários obedecem a um capataz somente se entre eles há um consenso de que é justo o sistema de promoções pelo qual um funcionário se torna capataz".

Dessa forma, percebe-se que esse tipo de autoridade é completamente oposto ao primeiro, tendo em vista que nesse tipo fica evidente que a autoridade legítima se baseia na aceitação do líder pelos membros da equipe, e não por força de ferramentas de coerção para manipulá-los.

Hollander (1964), em seus estudos, propõe a teoria das trocas, na qual enfatiza o equilíbrio entre expectativas dos subordinados e as respostas comportamentais oferecidas pelo líder como fator relevante para uma boa liderança; ou seja, indica que o líder terá maior aceitação tanto quanto maior for considerado facilitador dos objetivos almejados pelos liderados. Confirmando a ideia de Hollander (1964), House e Mitchel (1974) propuseram a teoria do caminho-objetivo, indicando que o líder não deve apenas conhecer os objetivos almejados por seus liderados, mas também desempenhar o papel de facilitador do percurso até o alcance das metas.

Motta (1995) afirma que a visão da legitimidade da liderança ou da autoridade com base na aceitação do líder pelo grupo condiciona considerar que boa parte do poder do líder fixa-se no próprio grupo. Essa ideia vai ao encontro da abordagem de Schein (1982), segundo a qual grande parte do poder do líder emerge dos próprios liderados que, se consentirem com os critérios que levaram o líder à posição de autoridade, irão aceitar obedecê-lo, caso contrário, 
não irão. A partir do modelo teórico apresentado, surge a seguinte hipótese teórica:

H1: Há maior aceitação de líderes quando ocorre maior consenso quanto à aceitação dos critérios que os levaram à liderança.

\subsection{Bases de poder e o poder legítimo}

French Jr. e Raven (1959) desenvolveram uma teoria sobre poder social, segundo a qual as relações entre as pessoas se fundamentam em trocas, com ênfase nas relações de influências, sustentadas por cinco bases de poder: poder de recompensa, poder coercitivo, poder legítimo, poder de perícia e poder de referência. Elas são as bases de apoio que uma pessoa usa para exercer poder sobre outra.

No Quadro 1 podem ser visualizadas as características de cada um desses poderes.

Quadro 1: Bases do poder (French Jr. e Raven, 1959)

\begin{tabular}{|c|c|c|c|c|}
\hline $\begin{array}{l}\text { Poder de } \\
\text { recompensa }\end{array}$ & $\begin{array}{l}\text { Poder coerci- } \\
\text { tivo }\end{array}$ & Poder legítimo & $\begin{array}{l}\text { Poder de } \\
\text { perícia }\end{array}$ & $\begin{array}{l}\text { Poder de } \\
\text { referência }\end{array}$ \\
\hline $\begin{array}{l}\text { Baseada na } \\
\text { habilidade } \\
\text { de recom- } \\
\text { pensar }\end{array}$ & $\begin{array}{l}\text { Envolve a } \\
\text { habilidade de } \\
\text { uma pes- } \\
\text { soa ter sob } \\
\text { seu controle } \\
\text { coisas impor- } \\
\text { tantes para } \\
\text { outra. Quem } \\
\text { exerce coerção } \\
\text { baseia-se na } \\
\text { expectativa do } \\
\text { outro de que } \\
\text { a pessoa pode } \\
\text { puni-lo se ele } \\
\text { falhar }\end{array}$ & $\begin{array}{l}\text { Reconheci- } \\
\text { mento de uma } \\
\text { pessoa de que } \\
\text { a outra tem o } \\
\text { poder legal, } \\
\text { concludente, } \\
\text { de influenciá-la } \\
\text { e que ela tem } \\
\text { por obrigação } \\
\text { aceitar essa } \\
\text { influência }\end{array}$ & $\begin{array}{l}\text { Baseia-se no } \\
\text { fato de uma } \\
\text { pessoa reco- } \\
\text { nhecer que a } \\
\text { outra domi- } \\
\text { na certo co- } \\
\text { nhecimento, } \\
\text { que é espe- } \\
\text { cialista em } \\
\text { determinado } \\
\text { assunto e, } \\
\text { que por isso, } \\
\text { não deve } \\
\text { questioná-la }\end{array}$ & $\begin{array}{l}\text { O poder de } \\
\text { influenciar } \\
\text { o outro } \\
\text { pela for- } \\
\text { ça do seu } \\
\text { carisma ou } \\
\text { por carac- } \\
\text { terísticas } \\
\text { pessoais } \\
\text { que são } \\
\text { admiradas } \\
\text { e servem } \\
\text { como refe- } \\
\text { rência }\end{array}$ \\
\hline
\end{tabular}

Fonte: Elaboração própria, 2016

Como se pode perceber, cada poder parte de um pressuposto baseado nas relações entre pessoas, sejam formas de relações boas, 
sejam ruins. As autoras acreditam que existem ainda muitas outras bases de poder que precisam ser identificadas e estudadas. Hinkin e Schriesheim (1989, p. 561), por exemplo, destacam que "apesar do número de tipologias ou modelos existentes, talvez a mais influente seja a de French e Raven".

É interessante salientar que, de forma ampla, as bases de poder legítimo e base de poder de perícia são consideradas como benéficas para a organização. Isso porque, segundo Yukl (1994, apud MARTINS, 2008), elas estão positivamente relacionadas com comprometimento e confiança organizacionais, e de acordo com Rahim (1989, apud MARTINS, 2008) se relacionam positivamente com a confiança do empregado. Porém, as bases de poder de coerção e de recompensa são consideradas amplamente como maléficas para a organização, pois estão associadas à resistência, o que para eles caracterizam-na como uma forma de conflito organizacional (JOHNSON; PAYNE, 1997, MARTINS, 2008).

Para otimizar as análises deste estudo, optou-se em realizar uma relação das bases de poder de French Jr. e Raven (1959), com a definição de autoridade legítima e ilegítima de Schein (1982). Na Figura 1, pode-se visualizar essa relação.

Figura 1: Relação da definição de autoridade defendida por Schein e bases do poder de French Jr. e Raven
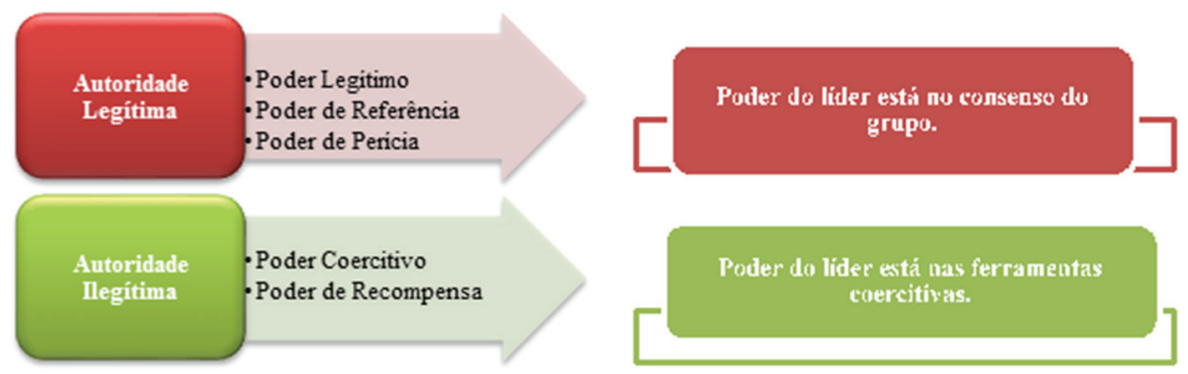

Fonte: Elaboração própria, 2016 
Poder e autoridade são temas interligados. Quanto mais se entender os caminhos que levam um líder a obter autoridade, mais se compreenderá o poder de liderar.

Rodrigues, Assmar e Jablonski (2003, p. 179) salientam que "um dos fenômenos que mais comumente ocorrem no relacionamento interpessoal é o fenômeno da influência social. Constantemente, estamos tentando influenciar outras pessoas e sendo por elas influenciados".

\subsection{Guarda Civil Municipal de Mossoró}

A fim de testar a hipótese levantada neste trabalho, a Guarda Civil Municipal de Mossoró (RN) (GCMM) foi escolhida como objeto de estudo. Fundada em 2009 por meio da Lei Complementar n. 037, de 14 de dezembro de 2009 (RIO GRANDE DO NORTE, 2009), possui hoje em torno de 275 guardas civis municipais efetivos, além do pessoal do setor administrativo, que é comissionado. A instituição foi escolhida por estar passando por um processo de mudança nos critérios para seleção das lideranças e consequentemente de mudança das lideranças em si. De 2009 até maio de 2016, a estrutura organizacional (operacional) da GCMM era composta, de forma sintética, pelo comandante (topo da hierarquia), seguido dos fiscais que comandavam os cinco pelotões da instituição e, após eles, os guardas civis. O critério que levou esses fiscais a posição de liderança foi unicamente a indicação política.

Porém, em 2014 a GCMM teve o Plano de Cargos, Carreira e Remunerações (PCCR) instituído por meio da Lei Complementar n. 98, de 24 de janeiro de 2014 (RIO GRANDE DO NORTE, 2014), e um dos artigos trata sobre os critérios para se estabelecerem os líderes de pelotões da instituição. De acordo com o PCCR, esses líderes são denominados inspetores e subinspetores e devem chegar à liderança mediante concurso interno, composto por quatro etapas: prova de tempo de serviço; prova de nível de escolaridade; prova de cursos técnicos na área de segurança; e prova de resistência física. O PCCR foi desenvolvido pelo sindicato da categoria ao longo de 2012 e 2013 e só foi aprovado e instituído após as negociações de uma greve realizada pela categoria em 2013. Em maio de 2016, o concurso para selecionar os inspetores e subinspetores foi realizado, 
e em junho do mesmo ano estes foram nomeados e tomaram posse nos cargos, substituindo os fiscais.

Dessa forma, pode-se perceber que o processo de mudança nos critérios para a seleção de líderes formais da instituição oferece uma oportunidade empírica para testar a hipótese teórica deste estudo (H1). Isso porque, ao se comparar o consenso em relação aos critérios adotados para selecionar os dois tipos de líderes, em um primeiro momento os antigos fiscais e num segundo os inspetores e subinspetores, com o nível de aceitação desses dois tipos de líderes, poderá se verificar se há concordância ou não quanto à hipótese teórica levantada a partir do modelo de Schein (1982).

\section{Metodologia}

\subsection{Tipo}

Este trabalho apresenta natureza descritiva, buscando expor características dos grupos estudados por meio de testes estatísticos com o intuito de confirmar ou refutar hipóteses levantadas sobre liderança, autoridade e poder.

Para as análises das hipóteses estatísticas as amostras foram codificadas. Cada profissional foi considerado como uma amostra e cada pergunta como uma variável. Desse modo, a matriz de dados multivariada foi composta por 50 amostras em estudo e 40 variáveis. Tomando as respostas das perguntas como referência, foram realizados os testes, os quais serão discutidos posteriormente. A análise dos dados se deu de forma quantitativa.

\subsection{Universo/amostra}

A organização estudada foi a Guarda Civil Municipal de Mossoró, localizada a $280 \mathrm{~km}$ de Natal, capital do Rio Grande do Norte. Atualmente a organização conta com um efetivo de 275 guardas, dos quais 50 participaram da pesquisa, número correspondente a $18,2 \%$ do universo.

A seleção dos entrevistados foi feita por conveniência, ou seja, de acordo com as possibilidades de acesso aos respondentes. A exceção foram os guardas que já assumiram o cargo de fiscais ou os que assumiram os cargos de inspetores e subinspetores, tendo em vista preservar ao máximo a confiabilidade das respostas. 


\subsection{Método de coleta}

Para a execução deste estudo foi realizada pesquisa documental, com vistas a ter acesso a informações pertinentes da Guarda Civil Municipal de Mossoró, como análise do site da instituição, leis que regulamentem a GCMM (como a Lei Complementar no 037 e a Lei Complementar no 98 , entre outras) e o edital do processo seletivo de inspetor e subinspetor.

Durante todo o mês de junho de 2016 também foi aplicado questionário estruturado, composto por 38 questões fechadas, assim distribuídas: quatro relacionadas à caracterização socioeconômica (de elaboração própria); duas relacionadas ao tempo de serviço e área de atuação na guarda civil (de elaboração própria); duas relacionadas à medição do consenso em relação à aceitação dos critérios que levaram os dois tipos de líderes à liderança, tendo sido desenvolvidas no modelo de escala Likert, ambas com 11 níveis de aceitação, indo de 0 até 10 - vale salientar que os critérios utilizados para selecionar os inspetores e os subinspetores, e que foram medidos, foram o nível de escolaridade, tempo de serviço, cursos técnicos na área e prova de resistência física, ao passo que os utilizados para escolher os antigos fiscais, e que foram medidos, se resumiam à indicação política ou do comando da guarda; e 30 relacionadas à medição do nível de aceitação da liderança dos dois tipos de líderes, como também a medição das bases de poder utilizadas pelos dois tipos de líderes. Para tanto, foi utilizada a Escala de Bases do Poder do Supervisor (EBPS) de Martins (2008), a qual foi amplamente validada em nível internacional e posteriormente no Brasil, tendo sido aplicada e testada estatisticamente com 312 trabalhadores brasileiros de diversos tipos de organizações. A escala EBPS adaptada e validada para trabalhadores brasileiros avalia quatro das cinco bases de poder propostas por French Jr. e Raven (1959), a saber: poder legítimo; poder de perícia; poder de coerção; e poder de recompensa. A medição da base de poder legítimo foi utilizada para a medição do nível de aceitação da liderança dos dois tipos de líderes.

Por fim, foi utilizado o método da observação participante, tendo em vista que um dos autores deste estudo trabalha na instituição atuando como guarda civil municipal, mais especificamente no 
cargo de subinspetor, portanto com contato direto e contínuo com os sujeitos da pesquisa. Esse método foi utilizado principalmente para coletar dados pertinentes em relação à GCMM que não ficaram acessíveis a partir da pesquisa documental.

\subsection{Método de análise}

A análise dos dados foi realizada de forma quantitativa. Foi utilizado o Software Excel para a tabulação, e o software estatístico $\mathrm{R}$ para a análise dos dados. Primeiramente foi desenvolvida uma análise descritiva dos dados socioeconômicos provenientes dos questionários, seguida de uma análise descritiva das variáveis utilizadas na composição dos construtos avaliados neste artigo, na qual foram analisadas as médias, medianas, quartis, desvios-padrão, assimetria e curtose. Depois foi feito o teste da hipótese H1, por meio de teste de hipótese de médias e variâncias amostrais pareadas, o qual foi executado no software estatístico R. O teste foi composto das seguintes etapas: primeiramente utilizou-se o teste de variâncias pareadas (no software estatístico R) para comparar o nível de consenso quanto à aceitação dos critérios que levaram os dois tipos de líderes (os antigos fiscais e os inspetores e subinspetores) à liderança, depois de identificar qual dos dois conjuntos de critérios apresenta o maior consenso quanto à sua aceitação, foi então aplicado o teste de médias pareadas (no software estatístico R) para comparar o nível de aceitação da liderança dos dois tipos de líderes. Quando identificado o tipo de líder mais aceito, foi realizada a seguinte análise a fim de refutar ou concordar com a hipótese H1: se o conjunto de critérios que apresenta o maior consenso em relação à sua aceitação for aquele que tiver sido utilizado para selecionar o tipo de líder identificado como mais aceito, então H1 é confirmada; caso contrário, H1 é refutada.

\section{ANÁliSES E DiSCUSSõeS}

\subsection{Descrição da amostra}

A amostra desta pesquisa é composta por 50 indivíduos de um universo de 275 guardas civis que compõem a Guarda Civil Municipal de Mossoró (GCMM), ou seja, 18,2\% do total. De acordo 
com as respostas, observou-se que a maioria dos respondentes $(62 \%)$ tem até um ano de tempo de serviço na instituição; $16 \%$ são do sexo feminino e $84 \%$ do gênero masculino; parte dos respondentes possui ensino médio completo (32\%), ao passo que a maioria $(68 \%)$ já possui curso superior ou pós-graduação completa; a média da renda familiar mensal varia de $R \$ 2000,00$ a $R \$ 3000,00$ (36\%), valor referente a segunda faixa de renda presente no questionário, e a média da idade é de 32 anos. Tais características evidenciam uma boa adequação da amostra para os procedimentos de análise. Os gráficos a seguir detalham os dados sociodemográficos da amostra.

Figura 2: Idade

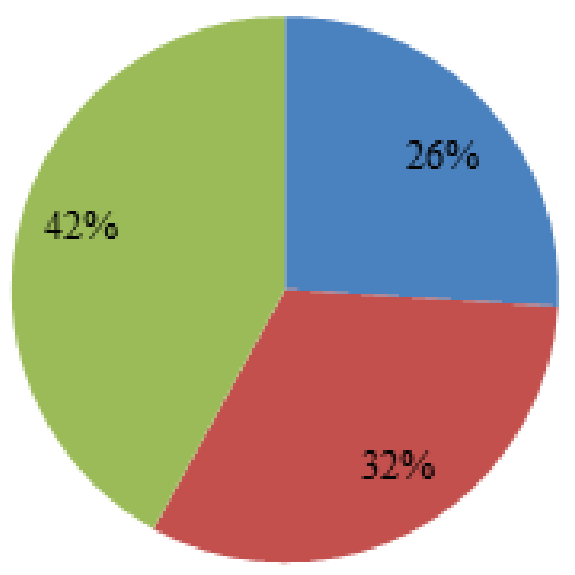

Até 28 anos

De 29 a 32 anos

Acim a de 32 anos

Fonte: Elaboração própria, 2016

Como pode ser observado na figura acima, e por meio da análise da média (32 anos) e do desvio-padrão em relação a essa média (apenas 6 anos), percebe-se que há uma concentração em torno da média, ou seja, uma uniformidade em relação à idade dos guardas civis que responderam o questionário. 
Figura 3: Gênero

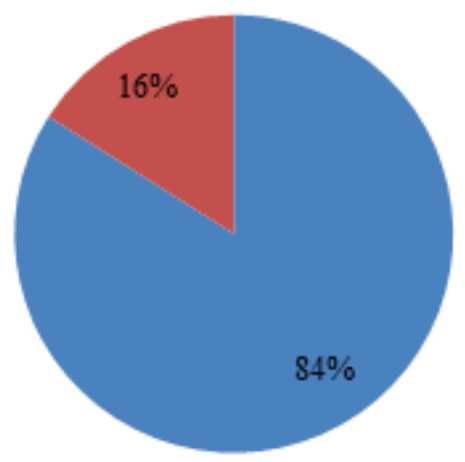

- Hom ens

Mulheres

Fonte: Elaboração própria, 2016

A partir do método da observação participante, percebeu-se que essa maioria tão evidente de homens pode ocorrer principalmente, entre outros fatores, devido à natureza operacional do serviço e ao alto risco à vida inerente a ele.

Figura 4: Escolaridade

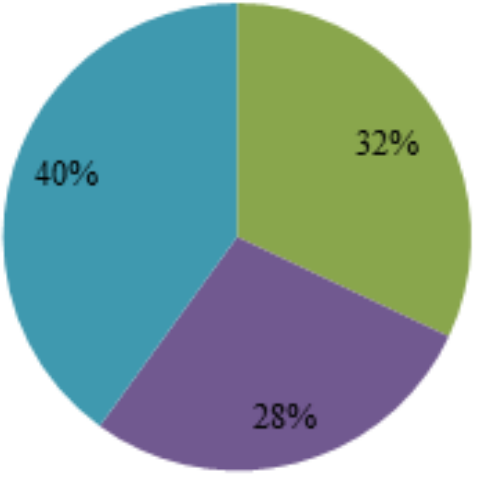

Analfabeto

Ens. Fundamental

Ens. Médio

Ens. Superior

- Especialização

Mestrado

Doutorado

Fonte: Elaboração própria, 2016.

Também foi percebido por meio da observação participante que um dos principais fatores que levaram à alta quantidade de guardas civis com nível superior e pós-graduação completa é a existência de um artigo no Plano de Cargos, Carreira e Remunerações (PCCR) que garante progressão funcional e salarial para àqueles que progredirem academicamente, partindo do nível médio até alcançar o doutorado. 
Figura 5: Faixa de renda familiar mensal

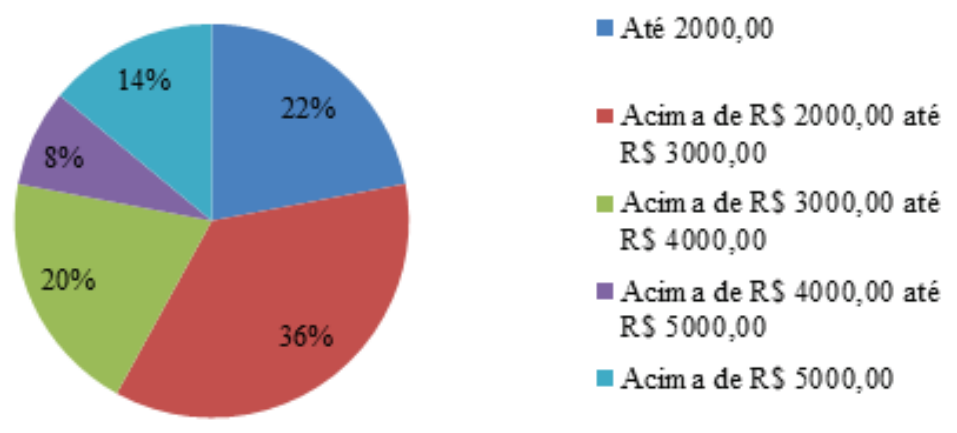

Fonte: Elaboração própria, 2016.

Foi identificado também pela observação participante que as diferenças nas faixas de renda percebidas, apesar de todos os respondentes exercerem o mesmo cargo, se dão, entre outros fatores, devido principalmente à progressão acadêmica e ao tempo de serviço, que levam a aumentos salariais, além do recebimento de horas extras trabalhadas.

Figura 6: Distribuição dos respondentes por pelotões

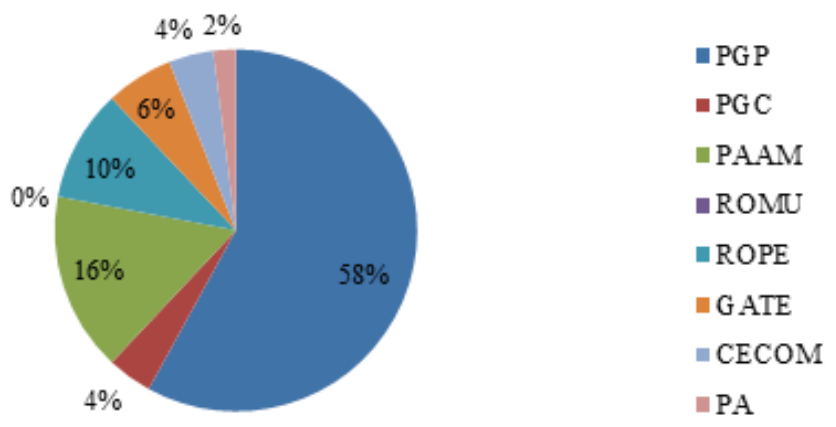

Fonte: Elaboração própria, 2016.

A GCMM é subdividida em oito pelotões: Pelotão da Guarda Patrimonial (PGP); Pelotão da Guarda Comunitária (PGC); Pelotão de Ação Ambiental (PAAM); Ronda Ostensiva Municipal (ROMU); Ronda Ostensiva de Prevenção Escolar (ROPE); Grupamento de 
Ações Táticas Especiais (GATE); Centro de Controle e Monitoramento (CECOM); e Pelotão Administrativo (PA). A alta quantidade de respondentes pertencentes ao PGP pode ser explicada devido ao tamanho desse pelotão, pois é o que possui a maior quantidade de guardas.

Figura 7: Tempo de serviço

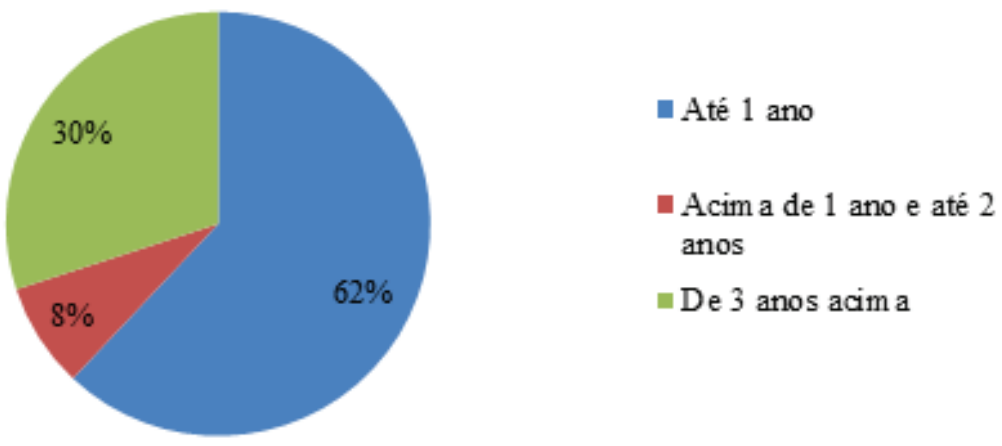

Fonte: Elaboração própria, 2016.

O pouco tempo de serviço informado pela maioria dos respondentes se dá, entre outros fatores, pela recente criação da GCM (2009) e pela realização do concurso por meio do qual a maioria dos guardas ingressou na instituição (2010).

\subsection{Análise das métricas dos construtos}

Esta etapa se dará em dois momentos. Primeiramente serão detalhadas as medidas descritivas das variáveis utilizadas para a elaboração dos construtos relativos à medição do consenso quanto à aceitação dos critérios utilizados para selecionar os antigos fiscais e os inspetores à posição de liderança. Na Tabela 1, serão detalhadas as medidas descritivas das variáveis utilizadas para a construção dos construtos relativos à medição da aceitação da liderança dos antigos fiscais e dos inspetores e subinspetores. 
Tabela 1: Medidas descritivas das variáveis utilizadas para a construção dos construtos relativos à medição do consenso quanto à aceitação dos critérios utilizados para selecionar os antigos fiscais e os inspetores à liderança

\begin{tabular}{|c|c|c|c|c|c|}
\hline Variáveis & Média & Mediana & Desvio & Assimetria & Curtose \\
\hline \multicolumn{6}{|c|}{$\begin{array}{l}\text { Variáveis do nível de consenso quanto à aceitação dos critérios que leva- } \\
\text { ram os inspetores e subinspetores à liderança }\end{array}$} \\
\hline Nível de escolaridade & 7.86 & 8 & 2.129 & -0.953 & 3.249 \\
\hline Tempo de serviço & 5.64 & 5.5 & 2.884 & -0.352 & 2.174 \\
\hline Cursos técnicos na ár & 7.24 & 8 & 2.37 & -0.678 & 2.339 \\
\hline $\begin{array}{l}\text { Prova de resistência } \\
\text { física }\end{array}$ & 6.8 & 7 & 2.68 & -0.713 & 2.617 \\
\hline \multicolumn{6}{|c|}{$\begin{array}{l}\text { Variáveis do nível de consenso quanto à aceitação dos critérios que leva- } \\
\text { ram os antigos fiscais à liderança }\end{array}$} \\
\hline $\begin{array}{l}\text { Indicação política ou do } \\
\text { comandante da Guarda }\end{array}$ & 3.88 & 4 & 3.426 & 0.5 & 1.989 \\
\hline
\end{tabular}

Fonte: Elaboração própria, 2016.

A escala utilizada variava de 0 a 10, e os níveis de análise se dão da seguinte forma: até 3,9 - baixa intensidade; de 4 até 6,9-moderada; de 7 até 8,9 - intensidade alta; e 9 ou superior - intensidade muito elevada.

As medidas mostram, por meio da média e da mediana, que o nível de respostas nas variáveis do nível de consenso quanto à aceitação dos critérios que levaram os inspetores e subinspetores à liderança ficou entre intensidade moderada e alta intensidade. Já em relação ao nível de respostas nas variáveis do nível de consenso quanto à aceitação dos critérios que levaram os antigos fiscais à liderança ficou em baixa intensidade. Isso indica desde já maior aceitação em média dos critérios que levaram os inspetores e subinspetores à liderança.

As medidas de desvio indicam que há maior convergência de posições dos respondentes em torno das médias, ou seja, maior consenso nas respostas às variáveis relacionadas aos inspetores e subinspetores do que nas respostas às variáveis relacionadas aos antigos fiscais. 
Quanto à curtose, a maior parte das variáveis evidenciou distribuição platicúrtica, com exceção da variável "Nível de escolaridade", que apresentou distribuição leptocúrtica. Por fim, em relação à assimetria, a maior parte das variáveis mostra distribuição assimétrica negativa, com exceção da variável "Indicação política ou do comandante da guarda", que apresenta distribuição assimétrica positiva.

Quanto às variáveis agregadas ou aos construtos, que foram construídos com base nas variáveis analisadas na Tabela 1, primeiramente o nível de consenso quanto à aceitação dos critérios que levaram os inspetores e subinspetores à liderança apresentou média e mediana com intensidade alta $(6.885,7)$. Quanto ao desvio padrão da variável agregada (1.545), este indica de forma ainda mais clara que há maior convergência em torno das médias, ou seja, maior consenso nas respostas às variáveis relacionadas aos inspetores e subinspetores do que nas respostas às variáveis relacionadas aos antigos fiscais. Por fim, apresentou distribuição platicúrtica (2.342) e distribuição assimétrica negativa (-0.32).

Já em relação ao constructo nível de consenso quanto à aceitação dos critérios que levaram os antigos fiscais à liderança, como só foi utilizada uma variável na construção deste ("Indicação política ou do comandante da guarda"), os dados descritivos são os mesmos que os da variável isolada.

A escala utilizada varia de 1 a 5 e possui os seguintes níveis de análise: valores maiores que 4 indicam intensa aceitação; e valores abaixo de 2,9 indicam baixa aceitação. As medidas mostram, por meio da média, que o nível de respostas nas variáveis do nível de aceitação da liderança dos inspetores e subinspetores foi moderada. Já em relação ao nível de respostas nas variáveis do nível de aceitação da liderança dos antigos fiscais, a maioria também foi moderada, muito embora tenha sido sensivelmente mais baixo que o nível de aceitação da liderança dos inspetores e subinspetores. A variável "Fazer-me perceber como eu deveria cumprir as exigências do meu trabalho" foi de baixa aceitação, indicando desde já maior aceitação em média da liderança dos inspetores e subinspetores.

As medidas de desvio indicam que a convergência de posições dos respondentes em torno das médias é levemente maior, ou seja, maior consenso nas respostas às variáveis relacionadas aos inspetores e subinspetores do que naquelas relacionadas aos antigos fiscais. 
Tabela 2: Medidas descritivas das variáveis utilizadas para a construção dos construtos relativos à medição da aceitação da liderança dos antigos fiscais e dos inspetores e subinspetores

\begin{tabular}{|c|c|c|c|c|c|}
\hline Variáveis & Média & $\begin{array}{l}\text { Media- } \\
\text { na }\end{array}$ & Desvio & Assimetria & Curtose \\
\hline \multicolumn{6}{|c|}{ Variáveis do nível de aceitação da liderança dos inspetores e subinspetores } \\
\hline $\begin{array}{l}\text { Fazer-me sentir que tenho com- } \\
\text { promissos a cumprir }\end{array}$ & 3.68 & 4 & 0.978 & -1.14 & 4.247 \\
\hline $\begin{array}{l}\text { Fazer-me perceber como eu } \\
\text { deveria cumprir as exigências do } \\
\text { meu trabalho }\end{array}$ & 3.66 & 4 & 1.042 & -0.473 & 3.205 \\
\hline $\begin{array}{l}\text { Fazer-me perceber que eu tenho } \\
\text { responsabilidades a cumprir }\end{array}$ & 3.18 & 3 & 1.155 & -0.501 & 2.27 \\
\hline $\begin{array}{l}\text { Fazer-me reconhecer que eu } \\
\text { tenho tarefas para realizar }\end{array}$ & 3.3 & 4 & 1.111 & -0.595 & 2.321 \\
\hline \multicolumn{6}{|c|}{ Variáveis do nível da aceitação da liderança dos antigos fiscais } \\
\hline $\begin{array}{l}\text { Fazer-me sentir que tenho } \\
\text { compromissos a cumprir }\end{array}$ & 3.24 & 3.5 & 1.222 & -0.322 & 2 \\
\hline $\begin{array}{l}\text { Fazer-me perceber como eu } \\
\text { deveria cumprir as exigências } \\
\text { do meu trabalho }\end{array}$ & 2.96 & 3 & 1.277 & -0.215 & 1.742 \\
\hline $\begin{array}{l}\text { Fazer-me perceber que eu } \\
\text { tenho responsabilidades a } \\
\text { cumprir }\end{array}$ & 3.18 & 3 & 1.155 & -0.501 & 2.27 \\
\hline $\begin{array}{l}\text { Fazer-me reconhecer que eu } \\
\text { tenho tarefas para realizar }\end{array}$ & 3.3 & 4 & 1.111 & -0.595 & 2.321 \\
\hline
\end{tabular}

Fonte: Elaboração própria, 2016.

Quanto à curtose, a maior parte das variáveis apresentou distribuição platicúrtica, com exceção de "Fazer-me sentir que tenho compromissos a cumprir" e "Fazer-me perceber como eu deveria cumprir as exigências do meu trabalho", relacionadas aos inspetores e aos subinspetores, que apresentaram distribuição leptocúrtica. Por fim, em relação à assimetria, todas as variáveis apresentam distribuição assimétrica negativa.

Quanto às variáveis agregadas, ou aos construtos, que foram construídos a partir das variáveis analisadas na Tabela 2, primeira- 
mente o nível de aceitação da liderança dos inspetores e subinspetores apresentou média com intensidade moderada (3.645), assim como quando analisadas cada variável de forma isolada. Quanto ao desvio-padrão da variável agregada (0.842), este indica de forma ainda mais clara que há maior convergência em torno das médias, ou seja, maior consenso nas respostas às variáveis relacionadas aos inspetores e subinspetores do que naquelas relacionadas aos antigos fiscais. Por fim, apresentou distribuição leptocúrtica (5.145) e distribuição assimétrica negativa (-1.105).

O nível de aceitação da liderança dos antigos fiscais também apresentou média com intensidade moderada (3.17); entretanto, quando comparadas as duas médias (inspetores e subinspetores: 3.645; antigos fiscais: 3.17), percebe-se que a média de aceitação da liderança dos antigos fiscais é sensivelmente mais baixa que a dos inspetores e subinspetores. Em relação ao desvio-padrão da variável agregada (1.045), este confirma a indicação de que há maior convergência em torno das médias, ou seja, maior consenso nas respostas às variáveis relacionadas aos inspetores e subinspetores do que nas relacionadas aos antigos fiscais. Por fim, apresentou distribuição platicúrtica (2.411) e distribuição assimétrica negativa (-0.437).

\subsection{Análise das hipóteses}

A fim de refutar ou confirmar a hipótese H1 estatisticamente há maior aceitação de líderes quando ocorre maior consenso quanto à aceitação dos critérios que os levaram à liderança -, formulada com base nos pressupostos teóricos de Schein (1982), primeiramente utilizou-se o teste de variâncias pareadas (var. test no software estatístico R), conforme mostra a Tabela 3, para medir a igualdade dos níveis de consenso quanto à aceitação dos critérios que levaram os dois tipos de líderes (os antigos fiscais e os inspetores e subinspetores) à liderança, para que, dessa forma, com o auxílio das médias e desvios-padrão, identificar qual conjunto de critérios pode ser considerado o detentor do maior consenso quanto à sua aceitação. 
Tabela 3: Teste de variâncias

\begin{tabular}{l|l|l|l}
\hline Teste aplicado & P-valor & Intervalo de confiança & Resultado \\
\hline $\begin{array}{l}\text { Teste de variân- } \\
\text { cias pareadas }\end{array}$ & $1.228 \mathrm{e}-07$ & $2.789611-8.662602$ & $\begin{array}{l}\text { As variâncias são } \\
\text { diferentes }\end{array}$ \\
\hline
\end{tabular}

Fonte: Elaboração própria, 2016.

De acordo com os resultados, se rejeita a igualdade das variâncias, pois o p-valor é bem menor que 0.05 e complementarmente o 1 não está contido no intervalo de confiança, significando que as variâncias não são iguais, ou seja, não são homocedásticas.

Acrescentando a essa análise as médias de aceitação dos critérios que levaram os dois tipos de líderes à liderança (antigos fiscais: 3.88; e inspetores e subinspetores: 6.885), como também os desvios-padrão em relação a essas médias, ou seja, o consenso dos liderados (antigos fiscais: 3.426; e inspetores e subinspetores: 1.545), fica claro que o conjunto de critérios que apresenta de forma notória o maior nível de aceitação é o conjunto de critérios utilizado para selecionar os inspetores e subinspetores, como também, é este que apresenta, também de modo evidente, a maior convergência em relação à média, ou seja, o maior consenso quanto à sua aceitação. Pode-se perceber até mesmo que o nível de aceitação dos critérios que levaram os antigos fiscais à liderança é muito baixo, sugerindo uma rejeição dos tais por parte dos liderados; além disso, o nível de consenso em relação a esse baixo nível de aceitação foi consideravelmente menor.

Depois de ter identificado qual dos dois conjuntos de critérios apresenta o maior consenso quanto à sua aceitação, foi então aplicado o teste de médias pareadas (t.test no software estatístico $\mathrm{R})$ para testar a igualdade das médias dos níveis de aceitação da liderança dos dois tipos de líderes. Dessa forma, com o auxílio das médias, buscou-se perceber qual dos dois tipos de líderes possui maior aceitação. 
Tabela 4: Teste de médias

\begin{tabular}{l|l|l}
\hline Teste aplicado & P-valor & Resultado \\
\hline Teste de médias pareadas & 0.01409 & As médias são diferentes \\
\hline
\end{tabular}

Fonte: Elaboração própria, 2016.

De acordo com os resultados, rejeita-se a hipótese de que as médias de aceitação da liderança dos antigos fiscais e dos inspetores e subinspetores são iguais, pois o p-valor é menor do que 0.05.

Atrelando a essa análise as médias de aceitação da liderança dos dois tipos de líderes (antigos fiscais: 3.17; e inspetores e subinspetores: 3.645) - vale lembrar que tais médias foram extraídas a partir de uma escala que variava de 1 a 5 -, fica evidente que os líderes que apresentam de forma considerável o maior nível de aceitação de sua liderança são os inspetores e subinspetores.

Dessa forma, os testes estatísticos realizados, bem como os dados descritivos (médias e desvio- padrão), possibilitam a confirmação da hipótese H1, pois os líderes que apresentaram maior aceitação da sua liderança foram de fato selecionados pelo conjunto de critérios que apresentou o maior consenso em relação à sua aceitação, ou seja, os inspetores e subinspetores, e os critérios que os selecionaram. Portanto, pode-se afirmar que há maior aceitação de líderes quando ocorre maior consenso quanto à aceitação dos critérios que os levaram à liderança, extraída a partir de pressupostos teóricos de Schein (1982).

\subsection{Análise das bases de poder dos antigos fiscais e dos ins- petores e subinspetores}

A Tabela 5 apresenta os resultados, em média, da utilização das quatro bases de poder constantes na Escala de Bases do Poder do Supervisor (EBPS) de Martins (2008), pelos dois tipos de líderes da GCMM (os antigos fiscais e os inspetores e subinspetores). 
Tabela 5: Médias das bases de poder dos antigos fiscais e dos inspetores e subinspetores

\begin{tabular}{l|l|l}
\hline & Antigos fiscais & Inspetores e subinspetores \\
\hline Base de poder legítimo & 3,17 & 3,65 \\
\hline Base de poder de perícia & 3,19 & 3,66 \\
\hline Base de poder de coerção & 2,44 & 2,17 \\
\hline Base de poder de recompensa & 1,89 & 2,10 \\
\hline
\end{tabular}

Fonte: Elaboração própria, 2016.

A escala utilizada varia de 1 a 5 e tem os seguintes níveis de análise: valores maiores que 4 indicam que a base de poder é bastante utilizada, e valores menores do que 2,9 apontam que ela é pouco utilizada. Foi feita a análise das bases de poder utilizadas pelos dois tipos de líderes da GCMM.

No que se refere à base de poder legítimo, ou seja, aquela que, segundo French Jr. e Raven (1959 apud MARTINS, 2008, p. 24), parte do "reconhecimento de uma pessoa de que a outra tem o poder legal de influenciá-la e que ela tem por obrigação aceitar esta influência" - em outras palavras, aquele que emerge da aceitação da liderança de alguém -, os dois tipos de líderes utilizam-na de forma moderada, de acordo com a avaliação de seus liderados; os inspetores e subinspetores fazem uso dela de modo consideravelmente superior, aproximando-se de uma avaliação considerada de alta intensidade.

Quanto à base de poder de perícia, aquela que, de acordo com French Jr. e Raven (1959 apud MARTINS, 2008, p. 24), se baseia no "reconhecimento por parte de uma pessoa de que a outra domina certo conhecimento e que, por isto, não deve ser questionada", os dois tipos de líderes também utilizam-na de forma moderada, de acordo com a avaliação de seus liderados; os inspetores e subinspetores também fazem-no de maneira consideravelmente superior, e mais uma vez aproximando-se de uma avaliação considerada de alta intensidade.

Em relação à base de poder de coerção, aquela que, para French Jr. e Raven (1959 apud MARTINS, 2008, p. 24), se baseia na “habilidade de uma pessoa ter sob seu controle coisas importantes que ameaçam a outra", os dois tipos de líderes utilizam-na pouco, de acordo com a 
avaliação de seus liderados; os inspetores e subinspetores recorrem a ela de forma levemente menor que os antigos fiscais.

Por fim, quanto à base de poder de recompensa, aquela que, segundo French Jr. e Raven (1959 apud MARTINS, 2008, p. 24), se baseia no "poder de fornecer à outra pessoa algo considerado um prêmio ou capacidade de remover ou diminuir punições destinadas ao outro", os dois tipos de líderes utilizam-na pouco, de acordo com a avaliação de seus liderados; os inspetores e subinspetores fazem uso dela de forma levemente maior que os antigos fiscais.

De forma geral, percebe-se a partir desse diagnóstico da utilização das quatro bases de poder constantes na Escala de Bases do Poder do Supervisor (EBPS) de Martins (2008), pelos dois tipos de líderes que já passaram pela instituição, que as bases de poder mais utilizadas - a de poder legítimo e a de poder de perícia - são benéficas para a organização, pois segundo Yukl (1994, apud MARTINS, 2008) estão positivamente associadas a comprometimento e confiança organizacionais e, de acordo com Rahim (1989, apud MARTINS, 2008), se relacionam positivamente com a confiança do empregado. Semelhantemente, as duas bases de poder menos utilizadas - a de poder de coerção e de poder de recompensa - são maléficas para a organização, pois de acordo com Johnson e Payne (1997, apud MARTINS, 2008), estão associadas a resistência, o que para eles caracterizam-na como forma de conflito organizacional.

\section{ConClusão}

A partir dos resultados obtidos nesta pesquisa, pode-se confirmar a hipótese teórica formulada a partir de pressupostos de Schein (1982) escritos há mais de três décadas, mas que, como pode ser visto, permanecem explicando a realidade organizacional, ao menos na instituição estudada. A hipótese teórica testada e confirmada afirma que há maior aceitação de líderes quando ocorre maior consenso quanto à aceitação dos critérios que os levaram à liderança. Dessa forma, percebe-se a importância dos processos de estabelecimento de critérios para escolher os indivíduos que assumirão papéis de liderança nas organizações, tendo em vista potencializar a sua base de poder legítima e, assim, o seu nível de influência perante os subordinados. Esse cuidado possibilita que os 
novos líderes definam como fontes principais do seu poder aquelas que são benéficas à organização e aos subordinados, como o poder legítimo e o de perícia, que são fontes de poder características da autoridade legítima, e não as que causam conflitos na organização, como o poder coercitivo e de recompensa, que são características da autoridade ilegítima.

Desse modo, percebe-se a importância de desenvolver estratégias para estabelecer critérios de seleção de lideranças que sejam aceitos pelos subordinados, de forma a possibilitar a opinião destes na sua formulação, sob pena de impactar negativamente a aceitação dos líderes selecionados, caso não se definam critérios aceitos pelos subordinados.

Com base na relação conceitual estabelecida no referencial teórico entre as bases de poder de French Jr. e Raven (1959) e as duas formas de autoridade de Schein (1982), observa-se que com aquelas utilizadas pelos dois tipos de líderes - poder legítimo e poder de perícia - a GCMM se aproxima muito mais de um modelo de autoridade legítima, que é aquele, segundo Schein (1982), que se fundamenta na aceitação do líder pelos membros da equipe, e não por força de ferramentas de coerção para manipular estes, do que de um modelo de autoridade ilegítima, que se baseia no poder, ou seja, que se vale da força bruta, da manipulação de recompensas, punições e informações para controlar as pessoas e que tem como bases de poder a coerção e a recompensa.

Quanto às limitações deste trabalho, elas se apresentam em dois pontos principais. Primeiramente, quanto ao momento no qual os questionários sobre a aceitação dos líderes foram aplicados apenas um mês após a mudança de liderança -, ou seja, os antigos fiscais tinham deixado os cargos e os inspetores e subinspetores os substituíram. Isso pode ter influenciado a avaliação da aceitação dos dois grupos de líderes, pois o ideal seria que os novos líderes tivessem passado um período maior na liderança, a fim de possibilitar maior tempo para que os subordinados pudessem fazer uma avaliação mais segura da sua aceitação. Porém, se acredita que esse fator não invalida os resultados alcançados. A outra limitação diz respeito à amostra, que foi selecionada por conveniência devido às dificuldades de acesso aos guardas civis. 
Por fim, sugere-se que sejam desenvolvidos outros estudos em oportunidades similares à aproveitada nesta pesquisa, para confirmar ou refutar a hipótese levantada. Isso poderá ocorrer na mesma instituição investigada neste trabalho, quando os inspetores e subinspetores tiverem passado um período mais extenso na liderança, a fim de comparar os resultados nos dois momentos.

\section{REFERÊNCIAS}

BERGAMINI, C. W. Liderança: a administração do sentido. Revista de Administração de Empresas, São Paulo, v. 34, n. 3, p. 102-114, maio/jun. 1994. Disponível em: <http://www. scielo.br/pdf/rae/v34n3/a09v34n3pdf>. Acesso em: 28 jul. 2016.

BORNSTEIN, S. M.; SMITH, A. F. Os enigmas da liderança. In: HESSELBEIN, F. et al. O líder do futuro. Tradução de Cyntia Azevedo. São Paulo: Futura, 1996. Cap. 29, p. 277-87.

RIO GRANDE DO NORTE. Lei Complementar nº 037, de 14 de dezembro de 2009. Jornal Oficial de Mossoró, Mossoró, 22 dez. 2009.

Lei Complementar nº 098, de 24 de janeiro de 2014. Jornal Oficial de Mossoró, Mossoró, 24 jan. 2014.

BRYMAN, A. Charisma and Leadership in Organizations. London: Sage, 1996.

CHIAVENATO, I. Gerenciando pessoas: o passo decisivo para a administração participativa. São Paulo: Makron Books, 1994.

DAFT, R. Leadership: Theory and Practice. Dryden Press: Fort Worth, 1999.

FRENCH JR., J. R. P.; RAVEN, B. The bases of social power. In: CARTWRIGHT, D. (Ed.). Studies in social power. Ann Arbor: University of Michigan Press, 1959. p. 150-167.

HINKIN, T. R.; SCHRIESHEIM, C. A. Development and application of new scales to measure the French and Raven (1959) bases of social power. Journal of Applied Psychology, Washington, DC - EUA, v. 74, n. 4, p. 561-567, 1989.

HOGAN, J.; HOGAN, R. Big five personality traits. In: GOETHALS, G. R.; SORENSON, G. (Eds.) Encyclopedia of Leadership. Thousand Oaks: SAGE Publications, 2004. p. 95-98.

HOLLANDER, E. P. Leaders, Groups and Influence. Oxford: University Press, 1964.

HOUSE, R. J.; MITCHEL, T. R. Path-goal theory of leadership. Contemporary Business, v. 3, Seattle - Washington, D.C. - EUA, p. 81-98, 1974.

MARTINS, M. C. F. Bases do poder organizacional. In: SIQUEIRA, M. M. M. et al. Medidas do comportamento organizacional: ferramentas de diagnóstico e gestão. Porto Alegre: Armed, 2008. p. 21-28.

MOTTA, P. R. Gestão contemporânea: a ciência e a arte de ser dirigente. Rio de Janeiro: Record, 1995. 
NIRENBERG, J. Leadership effectiveness. In: GOETHALS, G. R.; SORENSON, G. (Ed.). Encyclopedia of Leadership (v. 1-4). Thousand Oaks: SAGE Publications, 2004. p. 844-852.

ROBBINS, S. O comportamento organizacional. Rio de Janeiro: Livros Técnicos e Científicos, 1999.

RODRIGUES, A.; ASSMAR, E. M. L.; JABLONSKI, B. Psicologia social. 22. ed. Petrópolis: Vozes, 2003.

SCHEIN, E. H. Psicologia Organizacional. Rio de Janeiro: Prentice-Hall do Brasil, 1982. Liderança e Cultura Organizacional. In: HESSELBEIN, F.; GOLDSMITH, M.; BECKHRD, R. O líder do futuro. São Paulo: Futura, 1996. p. 81-90.

Organizational Culture and Leadership. San Francisco: Jossey-Bass, 2004. . Cultura Organizacional e Liderança. São Paulo: Atlas, 2009.

VERGARA, S. C. Gestão de pessoas. 2. ed. São Paulo: Atlas, 2003.

YUKL, G. How leaders influence organizational effectiveness. The Leadership Quarterly, Reino Unido, v. 19, n. 6, p. 708-722, 2008.

Recebido em: 13-12-2016

Aprovado em: 24-4-2017

Avaliado pelo sistema double blind review.

Editor: Elmo Tambosi Filho

Disponível em http://mjs.metodista.br/index.php/roc 